\title{
Discrepancy Between Self-Report and School-Record Grade Point Average: Correlates With Psychosocial Outcomes Among African American Adolescents'
}

\author{
MarC A. ZimMERMAN, ${ }^{2}$ Cleopatra Howard CaldWEll, \\ AND DEBRA HILKENE BERNAT \\ Department of Health Behavior and Health Education \\ University of Michigan, Ann Arbor
}

\begin{abstract}
The purpose of this study is to better understand the implications for using self-reported grade point average (GPA) versus school-record GPA in academic achievement research. First, we found that nearly half the youths interviewed overreported their GPAs by at least 2 half grades. Second, youth who overreported their GPAs also reported less psychological distress, more successful academic beliefs, and fewer problem behaviors. Third, we found that self-reported GPA was associated with all 3 sets of variables, but school-record GPA was associated with only problem behaviors. The findings suggest that it may be useful for researchers to consider how different measures of GPA may influence their results.
\end{abstract}

Scholastic grade-point average (GPA) is one of the most frequently used measures in academic achievement research. It also has been found to be associated consistently with numerous psychosocial outcomes, such as academic beliefs, psychological distress, and problem behaviors among adolescents (Barber \& Olsen, 1997; Brook \& Newcomb, 1995; Joseph, 1996; Lent, Brown, \& Larkin, 1984; Musgrave-Marquart, Bromley, \& Dalley, 1997; Phinney, Cantu, \& Kurtz, 1997; Roeser, Midgley, \& Urdan, 1996; Schulenberg, Bachman, O’Malley, \& Johnston, 1994; Windle \& Windle, 1996). Most of this research relies on student self-reports of GPA to represent academic performance when used as an outcome or a predictor of other outcomes (Barber \& Olsen, 1997; Joseph, 1996; Mounts \& Steinberg, 1995; Rosenberg, Schooler, \& Schoenbach, 1989; Schulenberg et al., 1994). Studies of the accuracy of self-reported GPA when compared to more

'This research was funded by the National Institute on Drug Abuse Grant \#DA07484. The views or policies expressed do not necessarily reflect the views or policies of the National Institute on Drug Abuse. The authors would like to thank the Projects for Urban and Regional Affairs at the University of Michigan-Flint for their work on this project, and the Flint Community Schools and the students for their cooperation and time. We also would like to thank the anonymous reviewers for their thoughtful and helpful comments on earlier drafts of the manuscript.

${ }^{2}$ Correspondence concerning this article should be addressed to Marc A. Zimmerman, Department of Health Behavior and Health Education, School of Public Health, University of Michigan, Ann Arbor, MI 48109-2029. E-mail: marcz@umich.edu

Joumal of Applied Social Psychology, 2002, 32, 1, pp. 86-109.

Copyright $\odot 2002$ by V. H. Winston \& Son, Inc. All rights reserved. 
objective measures, such as school records, indicate that some students overestimate their past academic achievement (Alexander, Entwisle, \& Bedinger, 1994; Dobbins, Farh, \& Werbel, 1993; Frucot \& Cook, 1994; Martin \& Nagao, 1989; Trice, 1990). This research is typically concerned with the degree to which student self-reports are reliable or unreliable when compared to more objective measures.

Fetters, Stowe, and Owings (1984) found that African American students' responses were more discrepant than were those of White students. One interpretation of this finding is that African American students may be more dishonest than White students in reporting their GPAs. This conclusion, however, is misleading because it is not clear why African American students may have responded in the way that they did. Rarely do researchers consider whether or not the observed discrepancy between self-reported and school-record GPA may be an indication of something other than school performance. It is possible, for example, that selfreported GPA among African American students may serve as a proxy for their perception of their academic ability, or perhaps the students' desire to appear more academically oriented, especially within the context of an interview situation. The degree to which patterns of reliable or unreliable self-reports of GPA are related to other individual characteristics and behaviors has not been explored. These issues are particularly vital when considering the self-report behaviors of African American students because of the legacy of mistrust of researchers among African Americans based on the Tuskegee syphilis study (Gamble, 1993).

The Tuskegee syphilis study was initiated by the U.S. Public Health Service in 1932 and serves as the basis for the federal government strengthening regulations to protect research participants because of the abuses to African American men revealed during the course of this 40-year study (Armstrong, Crum, Reiger, Bennett, \& Edwards, 1999; Gamble, 1993; Thomas \& Quinn, 1991). Attempts to create a safe environment for African American students to self-disclose within the context of most survey research are not reported typically. The influence of matching or not matching interviewers and respondents by race and gender, for example, is rarely discussed in published research involving African Americans. Yet, previous research has indicated that African Americans respond differently with African American interviewers than they do with White interviewers on sensitive issues (Caldwell, Jackson, Tucker, \& Bowman 1999; Schuman \& Converse, 1971; Schuman \& Hatchett, 1974). By not recognizing the influence of the interview situation itself, as well as the diversity that exists among African American students, conclusions about the meaning of the discrepancy found when using different methods for measuring GPA may be erroneous, with detrimental effects to the conclusions that researchers might draw from their studies.

The Black-White paradigm as the basis for understanding self-report discrepancies may not be informative about the patterns of reliable or unreliable selfreports among African American male and female students. Thus, it is also critical to consider the influences of gender-matching respondents and interviewers 
within the context of an interview situation because of the race-gender stratification that operates in this society. Although few studies have examined the influence of gender on the accuracy of GPA reporting, both males and females have been found to significantly overestimate their past academic achievement (Frucot $\&$ Cook, 1994). Frucot and Cook also found that males overreported their GPAs to a greater extent than did females.

Another limitation of current self-report of academic performance research is that little attention has been paid to the accuracy of high school students' reports of their GPAs. The few studies that have considered the relationship between self-report and school-record GPA among high school students have relied on correlational analyses alone (Dornbusch, Ritter, Leiderman, Roberts, \& Fraleigh, 1987; Windle \& Windle, 1996). A significant problem with this approach is that correlational analyses cannot adequately determine the extent to which individual students may be under- or overreporting their GPAs. In addition, the implications of using one measure versus another for predicting other outcomes have not been studied.

The purpose of the present study is to better understand the implications of using self-reported GPA versus school-record GPA among African American high school students. We first examine the degree of accuracy between selfreported and school-record GPA among African American high school students. Second, we study how the discrepancy between GPA is related to psychological distress, academic beliefs, and problem behaviors. Third, we also use structural equation modeling to examine how the two GPA measures are related differently to these outcomes, regardless of their discrepancy. Fourth, the influence of raceand gender-matching of students and interviewers is assessed to test possible alternative explanations for discrepancies found. This fourth analysis is vital to explore because racial mistrust and gender socialization are part of the consciousness of many African American adolescents within this society (Biafora, Tyler, Warheit, Zimmerman, \& Vega, 1993; Guthrie, Caldwell, \& Hunter, 1997).

This study extends the literature on the accuracy of self-reports by comparing different reporting groups of African American youth on many variables found to be associated with school failure and dropout. These variables (i.e., psychological distress, academic beliefs, problem behaviors) have not been included in the same study or within the same multivariate analysis in previous GPA discrepancy studies, nor has previous research included large numbers of African American high school students. Most of the research on GPA discrepancy has focused on White college or elementary-school students.

\section{Research on GPA Reporting Accuracy}

The accuracy of academic achievement self-report research indicates that self-reported and actual GPA are highly correlated $(r=.76$ to $.91, p<.05)$. 
Nevertheless, Dobbins et al. (1993) found that approximately one quarter of the college students they surveyed overreported their GPAs by more than 0.05 on a 4-point scale. Studies of younger and more diverse populations of students have yielded similar results. Alexander et al. (1994) studied the role of expectations in school performance among fourth graders and found that students overreported their average reading grade by 0.60 on a 4 -point scale. Further, the extent to which students accurately reported their past academic achievement varied by level of achievement (Dobbins et al., 1993; Dornbusch et al., 1987; Frucot \& Cook, 1994). Lower achieving youth overreported their GPAs to a greater extent than did higher achieving youth. Dobbins et al. found that GPA inflation was unusual among youth who had a school-record GPA of 3.00 or higher. Dornbusch et al. (1987) found that high school youth with mean grades of $C$ or below had a tendency to overreport their GPAs. Similarly, Frucot and Cook found that the greatest overreporting occurred for students with lower GPAs. Yet, studies that examine the correlation between self-reported and school-record GPA provide no information about mean differences between the two data sources.

Researchers have also found self-reported GPA to be associated with adolescent self-esteem, self-worth, academic efficacy, educational aspirations, school motivation, and school bonding (Barber \& Olsen, 1997; Brook \& Newcomb, 1995; Owens, 1994; Phinney et al., 1997; Rosenberg et al., 1989). These findings suggest that GPA may serve a protective role in relation to social competency. Similarly, low GPA has been associated with delinquency, alcohol and substance use, psychological distress, and aggressive and violent behaviors (Joseph, 1996; Schulenberg et al., 1994; Windle \& Windle, 1996). Few of these researchers, however, have questioned the veracity of their GPAs data.

A common concern of self-report data is social desirability (Crowne \& Marlowe, 1964). Socially desirable responding refers to the bias in self-report data accounted for by respondents' desire to look good. Crowne and Marlowe suggested that socially desirable responding is related to respondents' need for self-protection and social approval. Social desirability is particularly problematic when (a) respondents feel little or no threat of researchers verifying the information, and (b) questions pertain to the respondents' ability (Dobbins et al., 1993; Martin \& Nagao, 1989). The survey situation is especially vulnerable to self-report biases. Dobbins et al., for example, found that students tended to inflate their GPAs more on a research survey than on a job-application form. They suggested that students tended to inflate more on the research survey because they were told that their responses were confidential and would not be verified.

Respondents also tended to inflate their past achievement to a greater degree during a face-to-face interview than on a self-administered questionnaire in an effort to make a good impression on the interviewer (Martin \& Nagao, 1989). This may be particularly relevant for African American and female respondents 
because of the racial and gender dynamics in United States society. Unfortunately, most studies that utilize face-to-face interview procedures do not test for potential biases in self-reports as a result of race or gender matching of respondents and interviewers. Past experiences with Whites, especially White male authority figures, could have different influences on how an African American student responds in the interview situation. African American students who lack a strong sense of self, for example, may be more likely to underreport rather than overreport their GPAs, perhaps because of fear of being caught. On the other hand, those who engage in problem behaviors may overreport their GPAs as part of a pattern of risky behavior.

In the present study, we hypothesize that students who overreport their GPAs will indicate less psychological distress, more successful academic beliefs, and fewer problem behaviors than will students who accurately report their GPAs, regardless of the race or gender of the interviewer. This hypothesis is consistent with a social desirability explanation. We also expect that self-reported GPA will be more likely to be associated with these outcomes than will school-record GPA because the same method bias will be operating between outcomes and selfreported GPA.

\section{Method}

\section{Participants}

Our sample was selected from ninth-grade students from the four main public high schools in the second largest school district in a midwestern state. These schools included $80 \%$ African American students at the time of the study. We chose from students enrolled in the school system at the start of the fall of 1994 (9th grade) with eighth-grade GPAs of 3.00 and below. The grade cutoff was used because these students were participating in a 4-year longitudinal study investigating youth at risk for school failure or dropout. Students diagnosed as being either emotionally impaired (EI) or developmentally disabled (DD) were not included in the study. All youths who had GPAs of 3.00 or lower, who were not El or DD, or who were either White or African American were included in the study $(N=979)$, but $13 \%$ of them were omitted either because they left the school system before the study began $(n=52)$, they could not be found after several attempts $(n=67)$, or they refused to participate $(n=10)$. Thus, the study began with 850 ninth-grade youths (80\% African American) who represented $88 \%$ of all eligible youth. We had a response rate of $96 \%(N=812)$ from Year 1 to Year 2.

The data reported in this study are from Year 2 (1995-1996, 10th grade), but only included the 679 African American youth from the sample. Approximately equal numbers of males $(N=333)$ and females $(N=346)$ participated. 
The average age of the students was 15.1 years $(S D=0.63)$. The mean prestige score for the present sample was $39.91(S D=10.45)$, which corresponds to a skilled blue-collar occupation (e.g., machinist).

Students who had missing data for school-record or self-reported GPA $(n=$ 88) were omitted from this study. Differences between youth in the study and those excluded as a result of missing data were examined to determine if any bias may have resulted from the elimination of these students. To compare the youth included in the study who had complete GPA data with the 88 youth excluded as a result of missing GPA data on all outcome variables for this study, $t$ tests were conducted. Results indicate that youth who were missing GPA data engaged in more violent behaviors than did youth with GPA data, $t(60.95)=-2.10, p<.05$, but no other differences for any other study variable were found. Thus, the final sample size for the current study was limited to the 591 students who had complete GPA data.

\section{Procedure}

Data were collected during face-to-face interviews and from self-administered questionnaires and school district files. Project staff conducted the interviews during regular school hours. Students were taken to private areas within the school for the 50- to 60-min interview. Youth who were not available to be interviewed in school were interviewed in a community setting (e.g., community organization). Areas assessed during the interview included health issues, relationships with family and peers, school beliefs and achievement, delinquency, and psychological distress. After the interview, students completed a self-report questionnaire about alcohol and drug use. Youth were informed that all information they provided was confidential and that additional information would be obtained from school district records.

Interviewers were 15 trained African American and White males and females who conducted face-to-face interviews. All interviewers were hired from the surrounding communities and had obtained at least a high school diploma or a general education diploma (GED). Interviewers and youth were not matched for race or gender for practical reasons. The school system, for example, required us to collect data efficiently to minimize the disruption of school activities. In addition, the racial and gender distributions of youth differed by school, and we were able to collect data only from one school at a time. Because youth did not always keep their scheduled interview appointments, we could not have collected data efficiently if we did not use our full cadre of trained interviewers while we were in each school. Following this procedure, however, we tested for interviewer effects based on race and gender within the present study. However, we were not able to test for both interviewer race and gender effects together because cell sizes would be too small (e.g., fewer than 30 ). 
Table 1

Descriptive Statistics for Demographics, Psychological Distress, Academic Beliefs, and Problem Behaviors

\begin{tabular}{lrrrc}
\multicolumn{1}{c}{ Variable } & $M$ & $S D$ & Skewness & $\alpha$ \\
\hline Demographics & & & & \\
Age & 15.51 & 0.63 & 0.92 & - \\
School-record GPA ${ }^{2}$ & 1.58 & 0.85 & 0.34 & - \\
Self-reported GPA & 6.13 & 2.09 & -0.36 & - \\
Psychological distress & & & & \\
Self-acceptance & 4.47 & 0.72 & -1.44 & .71 \\
Depression & 1.84 & 0.88 & 1.16 & .83 \\
Anxiety & 1.75 & 0.82 & 1.37 & .82 \\
Active coping & 4.21 & 0.57 & -0.89 & .75 \\
Academic beliefs & & & & \\
School efficacy & 4.09 & 0.50 & -1.19 & .77 \\
Graduate high school & 4.68 & 0.67 & -2.02 & - \\
Attend trade school & 3.39 & 1.34 & -0.41 & - \\
Attend 4-year college & 4.05 & 1.12 & -0.92 & - \\
Problem behaviors & & & & .82 \\
Marijuana use & 6.13 & 6.25 & 0.96 & - \\
Alcohol use & 5.63 & 4.92 & 0.85 & - \\
Violent behaviors & 1.41 & 0.58 & 2.03 & .78 \\
Nonviolent delinquency & 1.34 & 0.53 & 2.52 &. \\
\hline
\end{tabular}

aThe data reported are based on a 4-point scale before recoding for creating discrepancy groups.

\section{Measures}

The means, standard deviations, skewness, and Cronbach's alphas (where appropriate) for all study variables are presented in Table 1. Descriptions of all study variables follow.

School-record GPA. Semester grades from the 1994-1995 school year were obtained from school records. Students' cumulative GPA for the year was calculated by taking the average of the fall and spring semesters. Although students who had a GPA of 3.00 or below in eighth grade were selected to participate in this study, students' actual grades for ninth grade ranged from 0.10 to 4.00 . 
School-record GPA was recoded into an ordinal scale based on grade-point-toletter conversion standards, so higher grades were represented by higher scores: $8=\mathrm{A}(3.70$ to 4.00$) ; 7=\mathrm{B}+(3.30$ to 3.69$) ; 6=\mathrm{B}(3.00$ to 3.29$) ; 5=\mathrm{B}-(2.70$ to $2.99) ; 4=\mathrm{C}+(2.30$ to 2.69$) ; 3=\mathrm{C}(2.00$ to 2.29$) ; 2=\mathrm{C}-(1.70$ to 1.99$) ; 1=\mathrm{D}$ or below ( 0.10 to 1.69$)$.

Self-reported GPA. During the fall of 1995, students were asked "Which grade best describes your average grade last year?: $1=\mathrm{A}(93$ to 100$) ; 2=\mathrm{A}-(90$ to 92$) ; 3=\mathrm{B}+(87$ to 89$) ; 4=\mathrm{B}(83$ to 86$) ; 5=\mathrm{B}-(80$ to 82$) ; 6=\mathrm{C}+(77$ to 79$)$; $7=\mathrm{C}(73$ to 76$) ; 8=\mathrm{C}-(70$ to 72$)$; or $9=\mathrm{D}(69$ or below $)$." We made two modifications to the self-reported GPA scale to make it parallel to the school-record GPA scale. Categories 1 and 2 were collapsed, and the scale was reverse-coded $(8=\mathrm{A}, 1=\mathrm{D})$ so that higher grades were represented by higher scores.

Accuracy of self-reported GPA. The accuracy of youth's self-reported GPA was determined by subtracting self-reported GPA from school-record GPA. The four reporting groups were identified as slight underreporters, accurate reporters, slight overreporters, and high overreporters. No youth underreported their GPAs by more than 2 half-grades, so no high underreporting group was defined. Slight underreporters (SU) consisted of youth who underreported their grade by two half grades. Thus, a slight underreporter may have reported a grade of $\mathrm{C}+$, but school records indicated a $B$ average. Accurate reporters (AR) included students who reported their GPAs within one half grade of the school-record GPA (e.g., C+ self-report and C school record). Slight overreporters (SO) included students who overreported their grades by two half grades. A slight overreporter, for example, may have reported a grade of $\mathrm{B}$, but school records indicated a $\mathrm{C}+$. High overreporters (HO) included youth who overreported their GPAs by three half grades or more from the school-record GPA (e.g., reported B+, but school records indicated $\mathrm{C}+$ ).

Psychological distress. The four psychological distress variables measured were self-acceptance, depressive symptoms, anxiety, and active coping. Selfacceptance was measured with four items using a 5-point bipolar scale from the Bentler Personality Inventory (Stein, Newcomb, \& Bentler, 1986). Students were asked whether they were happy or unhappy with themselves, discouraged or pleased with themselves, liked or disliked themselves, and regarded themselves as a failure or a success. Depression and anxiety were measured by the Brief Symptom Index (Derogatis \& Spencer, 1982). These two scales were each measured by six items using a 5-point Likert format ranging from 1 (not at all) to 5 (extremely). Active coping was measured using the John Henryism scale developed by James, Strogatz, Wing, and Ramsey (1987). Students were asked about their beliefs regarding hard work and achievement through eight items using a 5point Likert response scale ranging from 1 (not true) to 5 (very true).

Academic beliefs. The four academic beliefs measured were school efficacy, likelihood of graduating high school, likelihood of attending a trade school or 
community college, and likelihood of attending a 4-year college. School efficacy was measured with five items using a 5-point Likert format ranging from 1 (not true) to 5 (very true) that assessed one's confidence in doing well at school. Example items include, "If I have enough time, I can do a good job on all my school work" and "Even if the work in school is hard, I can learn it." Youth indicated on a single 5-point Likert scale item ranging from 1 (not at all likely) to 5 (very likely) the likelihood of graduating high school, attending a trade school or community college, and attending a 4-year university.

Problem behaviors. The four sets of problem behaviors measured were marijuana and alcohol use, violent behaviors, and nonviolent delinquent behaviors. Marijuana use was measured by the sum of three self-report items using a 7-point Likert format ranging from 1 (never) to $7(40+$ times). Students were asked how many times they had used marijuana in their lifetime, during the past 12 months, and during the past 30 days.

Alcohol use was measured with four self-report items: (a) ever drank alcohol (Yes or No) and frequency of use on a 7-point Likert scale ranging from 1 (never) to 7 (40+ times) for (b) lifetime use, (c) use in the past 12 months, and (d) use in the past 30 days. The four items were standardized and summed to form an alcohol index because, unlike the marijuana measure, the alcohol items did not all use the same rating scales. We added a constant of 4 to this summary score so that all scores would be positive.

Violent behaviors were measured by how often youth engaged in any of eight behaviors (e.g., carrying a weapon, using a weapon coercively, hurting someone badly enough for the person to require medical attention). The behaviors were rated on a 5-point scale ranging from 1 (never) to 5 ( 4 or more times). Nonviolent delinquent behaviors were measured from 10 self-report items that asked youth how often they had participated in property theft, property damage, and the sale of illegal drugs. These behaviors were rated on the same 5-point scale.

Results

Accuracy of GPA Reporting

Pearson product moment correlations were used to determine the correspondence between self-reported GPA and school records, as well as correlations between the two approaches and the selected psychosocial variables. The two methods of GPA data gathering are highly correlated $(r=.62, p<.001)$. Further assessments of the level of accurate reporting or overreporting indicated that most youth reported their GPAs within one half of the grade recorded in school district records $(52 \%, N=306)$. Nearly half $(48 \%, N=280)$ of the youth overreported their GPAs: $17 \%(N=98)$ by 2 half grades (e.g., student-reported GPA = $\mathrm{C}$, school-record GPA $=\mathrm{D}+)$ and $31 \%(N=182)$ by 3 half grades or more (e.g., 
student-reported GPA $=\mathrm{B}$-, school-record GPA $=\mathrm{C}$-). Less than $1 \%(N=5)$ of the respondents underreported their GPAs.

Based on a MANOVA analysis, we found that school-record GPA differed by reporting group, $F(3,590)=4.14, p<.01$. Post hoc tests reveal that youth who underreported their GPAs had significantly higher grades based on school records $(M=2.58, S D=0.45)$ than did those who accurately reported $(M=1.62$, $S D=0.96)$, slightly overreported $(M=1.68, S D=0.84)$, or highly overreported $(M=1.46, S D=0.62)$ their GPAs. When underreporters were omitted from the analysis (because only 5 underreporters were identified), no differences were found for school-record GPA across the accurate and two overreporting groups, $F(2,549)=2.12$, ns.

Chi-square analyses were used to determine whether males and females differed on how accurately they reported their GPAs. Results show that males and females were equally distributed across the four GPA reporting groups (underreporters to high overreporters), $\chi^{2}(3)=5.74, n s$. Youth who underreported their GPAs were omitted from subsequent analyses because they were too few in number.

\section{Correlates of Self-Report and School-Record GPA}

Table 2 provides the correlational results of the three sets of outcome variables and the two types of GPA reporting. Self-report GPA was significantly correlated with all measures of psychological distress and problem behaviors in the expected direction. In terms of academic beliefs, all measures were significant except the likelihood of attending a trade school. School-record GPA, however, was related only to problem behaviors and the likelihood of graduating high school, attending college, and not attending a trade school.

\section{GPA Discrepancy and Psychosocial Outcomes}

The three GPA reporting groups included in the following analyses were: (a) accurate reporters, (b) slight overreporters, and (c) high overreporters. Three MANOVAs were conducted to examine differences on the outcome variables across GPA reporting groups by gender. Post hoc univariate analyses were performed when differences were found by reporting groups. We used both Duncan and Scheffé post hoc tests, which produced similar results. Table 3 presents the results of these analyses by GPA reporting group.

Psychological distress. Youth in the three GPA self-report groups reported different levels of psychological distress (Wilks's $\Lambda=.96$ ), approximate $F(8$, $1090)=2.58, p<.01$. Univariate analyses revealed main effects for selfacceptance, $F(2,548)=3.34, p<.05$; anxiety, $F(2,548)=3.14, p<.05$; and active coping, $F(2,548)=6.25, p<.01$; but not for depression, $F(2,548)=2.49$, 
Table 2

Correlations of Study Variables by Self-Report and School-Record Grade Point Average (GPA)

\begin{tabular}{lcc}
\hline \multicolumn{1}{c}{ Study variable } & Self-report GPA & School-record GPA \\
\hline Psychological distress & $.14^{* *}$ & .08 \\
Self-acceptance & $-.10^{*}$ & -.03 \\
Depression & $-.11^{* *}$ & -.03 \\
Anxiety & $.13^{* *}$ & -.02 \\
Active coping & & \\
Academic beliefs & $.15^{* * *}$ & .06 \\
School efficacy & $.34^{* * *}$ & $.26^{* * *}$ \\
Graduate high school & -.03 & $-.10^{*}$ \\
Attend trade school & $.30^{* * *}$ & $.22^{* * *}$ \\
Attend 4-year college & & $-.23^{* * *}$ \\
Problem behaviors & $-.19^{* * *}$ & $-.18^{* * *}$ \\
Marijuana use & $-.20^{* * *}$ & $-.20^{* * *}$ \\
Alcohol use & $-.15^{* * *}$ & $-.15^{* * *}$ \\
Violent behavior & $-.17^{* * *}$ & \\
Nonviolent delinquency &
\end{tabular}

${ }^{*} p<.05 .{ }^{* *} p<.01 .{ }^{* * *} p<.001$.

$n s$. Post hoc tests indicate that youth who accurately reported their GPAs revealed less self-acceptance than did youth who highly overreported their GPAs, $F(2$, $551)=3.38, p<.05$. Youth who accurately reported their GPAs indicated more anxiety than did those who overreported their GPAs (slight and high overreporters), $F(2,551)=3.31, p<.05$. Youth who accurately reported their GPAs indicated less active coping than did youth who highly overreported their GPAs, $F(2$, $551)=6.51, p<.01$. A main effect for gender was also found (Wilks's $\Lambda=.98$ ), approximate $F(4,545)=3.06, p<.05$. Females reported more anxiety, $F(1$, $548)=8.86, p<.01$; and depression, $F(1,548)=11.96, p=.001$, than did males. No gender by reporting group interaction was found (Wilks's $\Lambda=.99$ ), approximate $F(8,1090)=0.78$, ns.

Academic beliefs. Youth in the three GPA reporting groups differed on their reported academic beliefs (Wilks's $\Lambda=.95$ ), approximate $F(8,1090)=3.60, p<$ .001 . Univariate main effects were found for school efficacy, $F(2,548)=3.33$, $p<.05$; likelihood of graduating high school, $F(2,548)=9.81, p<.001$; and likelihood of attending a 4-year college, $F(2,548)=5.92, p<.01$; but not for 
Table 3

Means of Outcome Variables by Grade Point Average Reporting Groups

\begin{tabular}{|c|c|c|}
\hline & $\mathrm{HO}$ & $\begin{array}{c}\text { Duncan } \\
\text { paired } \\
\text { comparisons }\end{array}$ \\
\hline \multicolumn{3}{|l|}{ Psychological distress } \\
\hline Self acceptance* & $4.39(0.73) 4.51(0.70) 4.57(0.70)$ & $\mathrm{AR}<\mathrm{HO}$ \\
\hline Depression & $1.93(0.92) 1.77(0.85) 1.75(0.83)$ & - \\
\hline Anxiety* & $1.84(0.86) 1.63(0.76) 1.67(0.79)$ & $\mathrm{AR}>\mathrm{SO}, \mathrm{HO}$ \\
\hline Active coping** & $4.13(0.58) 4.21(0.60) 4.33(0.52)$ & $\mathrm{AR}<\mathrm{HO}$ \\
\hline \multicolumn{3}{|l|}{ Academic beliefs } \\
\hline School efficacy* & $4.04(0.53) 4.16(0.42) 4.14(0.47)$ & $\mathrm{AR}<\mathrm{SO}, \mathrm{HO}$ \\
\hline $\begin{array}{l}\text { Graduate high } \\
\text { school** }\end{array}$ & $4.53(0.86) 4.69(0.70) 4.79(0.56)$ & $\mathrm{AR}<\mathrm{SO}, \mathrm{HO}$ \\
\hline Attend trade school & $3.26(1.35) 3.53(1.24) 3.46(1.36)$ & - \\
\hline $\begin{array}{l}\text { Attend 4-year } \\
\text { college** }\end{array}$ & $3.90(1.17) 4.16(1.02) 4.24(1.02)$ & $\mathrm{AR}<\mathrm{SO}, \mathrm{HO}$ \\
\hline \multicolumn{3}{|l|}{ Problem behaviors } \\
\hline Marijuana use & $6.08(6.20) 5.82(6.19) 6.11(6.37)$ & 一 \\
\hline Alcohol use & $5.96(4.97) 5.53(4.92) 5.04(4.79)$ & - \\
\hline Violent behaviors & $1.42(0.60) 1.35(0.47) 1.41(0.60)$ & - \\
\hline $\begin{array}{l}\text { Nonviolent } \\
\text { delinquency* }\end{array}$ & $1.38(0.53) 1.27(0.40) 1.28(0.52)$ & $\mathrm{AR}>\mathrm{HO}$ \\
\hline
\end{tabular}

Note. Standard deviations are presented in parentheses. $\mathrm{AR}=$ accurate reporters; $\mathrm{SO}=$ slight overreporters; $\mathrm{HO}=$ high overreporters.

${ }^{*} p<.05 .{ }^{* *} p<.01$.

likelihood of attending a trade school or community college, $F(2,548)=1.63$, $n s$. Post hoc tests indicate that students who accurately reported their GPAs had lower school efficacy than did students who overreported their GPAs (slight and high overreporters), $F(2,551)=3.46, p<.05$. Youth who accurately reported their GPAs said they were less likely to graduate from high school than did youth who overreported their GPAs (slight and high overreporters), $F(2,551)=9.86$, $p<.001$. Youth who accurately reported their GPAs said they were less likely to attend a 4-year college than did students who overreported their GPAs (slight and high overreporters), $F(2,551)=5.76, p<.01$. No main effect for gender (Wilks's $\Lambda=.99$ ), approximate $F(4,545)=1.17, n s$; and no gender by reporting group 
interactions were found (Wilks's $\Lambda=.98$ ), approximate $F(8,1090)=1.62$, ns. Table 3 reports the means and standard deviations for academic beliefs by reporting group.

Problem behoviors. Youth in the three GPA reporting groups differed on their reported problem behaviors (Wilks's $\Lambda=.97$ ), approximate $F(8,1086)=1.97$, $p<.05$. A univariate main effect was found for nonviolent delinquent behaviors, $F(2,546)=3.48, p<.05$; but not for marijuana use, $F(2,546)=0.09, n s$; alcohol use, $F(2,546)=1.95, n s$; or violent behaviors, $F(2,546)=0.66, n s$. Post hoc tests indicate that youth who accurately reported their GPAs reported more nonviolent delinquent behaviors than did youth who highly overreported their GPAs, $F(2$, $549)=3.02, p<.05$. Problem behavior means and standard deviations for each reporting group are listed in Table 3. A main effect for gender was found (Wilks's $\Lambda=.96$ ), approximate $F(4,543)=5.68, p<.001$. Females reported fewer violent, $F(1,546)=10.31, p=.001$; and nonviolent behaviors, $F(1,546)=17.25, p<$ .001 , than did males. No gender by reporting group interactions were found (Wilks's $\Lambda=.99$ ), approximate $F(8,1086)=0.92$, ns.

\section{Path Analysis for GPA and Psychosocial Outcomes}

Structural equation modeling (SEM) using maximum likelihood estimation (EQS program) was used to examine paths from GPA self-report and school records to three latent constructs: (a) psychological distress, (b) academic beliefs, and (c) problem behaviors. The model included the two GPA variables as exogenous variables. The indicators for the latent endogenous factor followed the grouping of variables in the MANOVAs. First, we examined the measurement model for the latent constructs. Next, we tested a model where all paths from school-record GPA to the three latent factors were included, but no paths from self-reported GPA were specified. The correlation between school-record GPA and self-reported GPA was included in this model. We then compared this model with a fully saturated model where both school-record GPA and self-reported GPA (and their correlation) and all paths from the GPA measures to the latent factors were included.

The measurement model indicated an overall good fit. The normed fit index (NFI) was .96, the nonnormed fit index (NNFI) was .97 and the comparative fit index (CFI) was .98. The chi square for the measurement model was 66.47 ( $d f=$ $37, p<.01$ ), and the chi-square/degrees of freedom index was 1.80 . The average root mean square residual (RMSR) was .04 (off diagonal was .05). All indicator variables loaded on their respective latent factor except likelihood of attending a trade school. Factor loadings ranged from .31 to .60 for psychological distress (absolute values), .02 to .63 for academic beliefs, and .61 to .66 for the problem behaviors construct. Anxiety and depression had positive loadings, and selfacceptance and active coping had negative loadings on the psychological distress 
construct. We decided to keep all of the indicator variables in the SEM even though some of the variables had lower than ideal loadings because the measurement model indicated a highly acceptable model, and we wanted to maintain consistency with our MANOVA analyses.

The first structural model tested included all paths from school-record GPA to the latent factors (and none from self-reported GPA). The only nonzero path was between school-record GPA and problem behavior. The chi square for the model was $145.31(d f=58, p<.01)$, and the chi-square/degrees of freedom ratio was 2.51. The average RMSR was .04 (off diagonal was .05). The NFI was .94, the NNFI was .94, and the CFI was .96 . When we tested this model (eliminating the nonsignificant paths) with the added paths from self-reported GPA to the latent constructs, the chi square for this second model improved to 99.20 ( $d f=55, p<$ .01 ), and the chi-square/degrees of freedom ratio was 1.80 . The average RMSR was .03 (off diagonal was .04). The NFI was .96, the NNFI was .97, and the CFI was .98 . This model was a better fit for the data, as indicated by the chi-square difference test, $\chi^{2}(3)=46.11, p<.01$.

The final nonzero (i.e., statistically significant) structural path coefficients of the model with paths from both measures of GPA to the latent variables are reported in Figure 1. Self-reported GPA had paths to psychological distress (-.15), academic beliefs (.41), and problem behaviors (-.17); while school-record GPA only had a path to problem behaviors (-.17). Specifically, higher self-reports of GPA were associated with less psychological distress, higher academic beliefs, and fewer problem behaviors. As with the self-reported GPA measure, the schoolrecord measure of GPA was inversely related to reports of problem behavior. Unlike the self-report measure of GPA, however, the school-record GPA was not related to any of the psychological distress or academic belief variables.

\section{Interviewer Effects}

We examined interviewer effects for self-report GPA. No main effects for interviewer race, $F(1,552)=0.01$, ns; or interviewer gender, $F(1,550)=1.34$, $n s$, were found; and no interviewer gender by respondent gender interaction was found, $F(1,550)=0.59, n s$. Analyses were also conducted to determine the effects of interviewer race and gender on all psychosocial variables. We conducted a two-way MANOVA to examine interviewer race and reporting group interaction and main effects. We also conducted a three-way MANOVA to examine interaction and main effects for interviewer gender, respondent gender, and GPA reporting group. MANOVA results indicate no interaction effects of interviewer race by reporting group (Wilks's $\Lambda=.99$ ), approximate $F(8,1086)=$ $0.41, n s$; and no main effects for interviewer race (Wilks's $\Lambda=.99), F(4,543)=$ $0.31, n s$, were found for problem behaviors. No interaction effects for interviewer race by reporting group were found for psychological distress (Wilks's $\Lambda=.98$ ), 


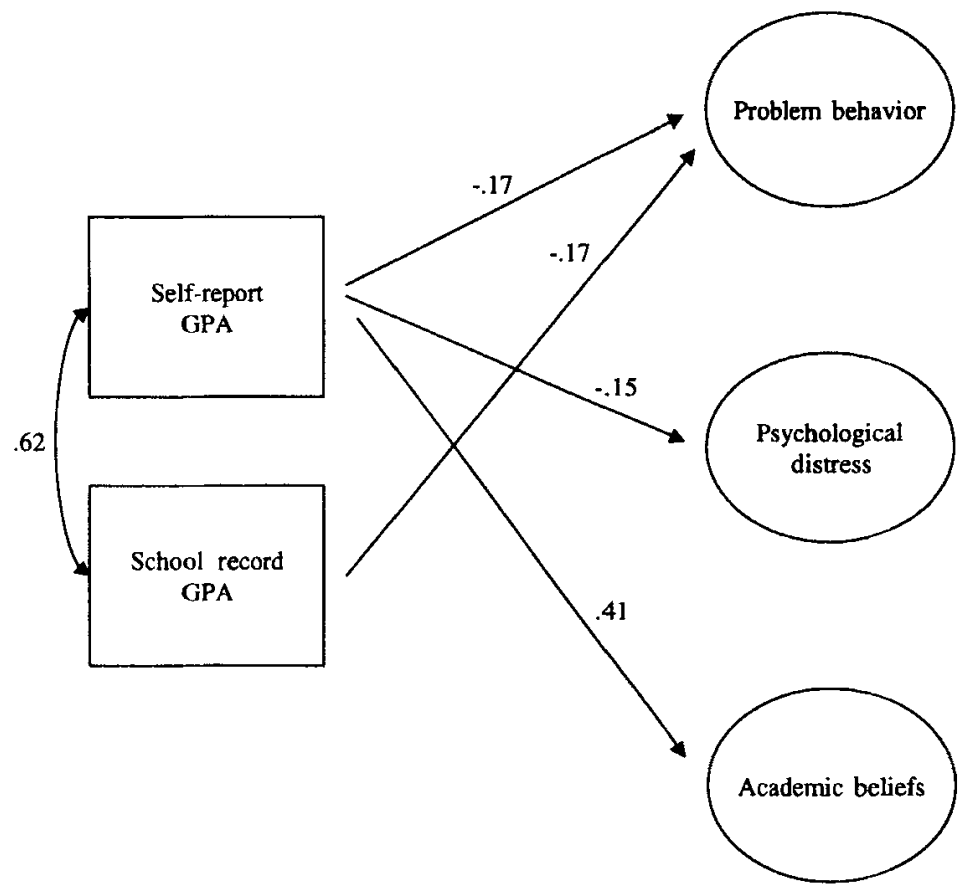

Figure 1. Structural path coefficients for predicting psychological distress, academic beliefs, and problem behavior based on self-report or school-record grade point average (GPA).

approximate $F(8,1090)=1.33, n s$. A main effect for interviewer race was found (Wilks's $\Lambda=.98), F(4,545)=2.78, p<.05$, for psychological distress. Only anxiety differed across groups in the univariate effects, $F(1,548)=4.56, p<.05$. Youth with African American interviewers were more likely to report less anxiety $(M=1.71, S D=0.80)$ than were youth with White interviewers $(M=1.83$, $S D=0.87$ ). Interviewer race by reporting group interaction effect (Wilks's $\Lambda=$ .98 ), approximate $F(8,1090)=1.10, n s$; and no main effects for interviewer race (Wilks's $\Lambda=1.0), F(4,545)=0.45, n s$, were found for academic beliefs.

The results of the $2 \times 2 \times 3$ MANOVA for interviewer and respondent gender and reporting group indicated no three-way interaction effects (Wilks's $\Lambda=.99$ ), approximate $F(8,1074)=0.96, n s$; and no interviewer gender by reporting group interaction effect (Wilks's $\Lambda=.99$ ), approximate $F(8,1074)=0.47, n s$, for problem behaviors. Other interaction effects were not found (e.g., interviewer gender by respondent gender) for problem behaviors. No main effect of interviewer gender was found for problem behaviors (Wilks's $\Lambda=.99$ ), $F(4,537)=0.60, n s$. A three-way interaction for psychological distress was not found (Wilks's $\Lambda=.99$ ), 
approximate $F(8,1078)=0.69$, ns; but the interviewer gender by respondent gender interaction was found (Wilks's $\Lambda=.98), F(4,539)=2.79, p<.05$. These results indicate that male respondents with female interviewers reported less anxiety, $F(1,550)=6.83, p<.01$; and depression, $F(1,550)=8.13, p<.01$, than did female respondents with female interviewers. The interviewer gender by reporting group interaction fell just beyond significance (Wilks's $\Lambda=.97$ ), approximate $F(8,1078)=1.95, p=.05$. No main effect for interviewer gender was found for psychological distress (Wilks's $\Lambda=.99$ ), $F(4,539)=1.55, n s$. No three-way interactions (Wilks's $\Lambda=.98$ ), approximate $F(8,1078)=1.06, n s$; interviewer gender by reporting group (Wilks's $\Lambda=.99$ ), approximate $F(8,1078)=0.62, n s$; or interviewer main effects (Wilks's $\Lambda=.99), F(4,539)=1.03$, ns, were found for academic beliefs. An interviewer gender by respondent gender interaction was found (Wilks's $\Lambda=.98), F(4,539)=2.67, p<.05$. The only univariate variable that differed was likelihood to attend a trade school or community college. However, post hoc tests did not reveal any difference across the four groups.

\section{Discussion}

The overall aims of this study were to increase our understanding of the accuracy of African American high school students' self-reports of their GPAs and the implications of the method of measurement for research. Study findings indicate that slightly more than half of the African American adolescents in this study accurately reported their academic performance within one half grade of their school-record GPA. A larger proportion of youth in our study overreported their grades than in previous research (Alexander et al., 1994; Dobbins et al., 1993). We also found that self-reported and school-record GPA were not as highly associated as reported in previous studies (Dornbusch et al., 1987; Frucot \& Cook, 1994; Windle \& Windle, 1996).

We also extended past research on the self-reported and school-record GPA discrepancy by examining a wider range of psychosocial variables. We found that the youth who accurately reported their GPAs were also likely to report more psychological distress, lower academic beliefs, and more delinquent behaviors than youth who overreported their GPAs. Youth in the overreporting groups tended to report more positive characteristics of themselves (e.g., selfacceptance, school efficacy) and fewer negative characteristics (e.g., delinquency, school dropout, anxiety). These results are consistent with researchers who have found associations between self-reported GPA and self-esteem (Connell \& Ilardi, 1987; Owens, 1994; Phinney et al., 1997; Rosenberg et al., 1989) and depressive symptoms (Barber \& Olsen, 1997; Windle \& Windle, 1996). We did not, however, find an association between gender and accuracy of selfreported GPA. Nor did we find interaction effects for gender and GPA discrepancy groups. Main effects by gender were found for some psychosocial outcomes 
that are consistent with past research (Ellickson, Saner, \& McGuigan, 1997; Grant et al., 1999; Hankins \& Abramson, 1999; Lewinsohn, Gotlib, Lewinsohn, Seeley, \& Allen, 1998; Wichstrom, 1999), but these were of less interest for the present study.

Our SEM results also indicate that self-reported and school-record GPA were associated differently with psychological distress and academic beliefs. Selfreported GPA was associated with problem behavior, psychological distress, and academic beliefs, but school-record GPA was only related to problem behaviors. This pattern of results is consistent with previous research. This suggests that self-reported GPA may inflate the probability of finding associations with other psychosocial variables among African American students. Either measure of GPA, however, appears to be useful for assessing the relationship of school achievement with problem behaviors among African American high school students. One implication of the SEM results is that studies using self-reported GPA may lead to different conclusions than if school-record GPA is used. Researchers who have examined connections between self-reported school achievement and problem behaviors may, however, be on firmer footing in their confidence in the results. This may be particularly true for studies that include African American youth. Nevertheless, future research would benefit from a more detailed examination of the empirical implications of measuring GPA using self-report methods.

Several explanations may account for our results. Social desirability is one explanation offered for GPA overreporting behavior (Dobbins et al., 1993; Martin \& Nagao, 1989). This explanation suggests that youth overestimate their ability to either protect their self-esteem or seek social approval. Although this research is based on data collected primarily from White students, it is possible that African American youth may be more inclined to provide socially desirable responses than Whites within the context of an interview (Mensch \& Kandel, 1988). It is likely that the interviewer in these situations is White, further distancing the interviewee and interviewer. Thus, African American youth may have less trust in the research process, distorting their self-reports to make a good impression on the interviewer and to maintain their own self-esteem (Johnson, Bachman, \& O'Malley, 1984).

This explanation, however, may not be completely consistent with our findings regarding interviewer race effects. African American adolescents' desire to look good to White interviewers because of race dynamics was not supported in this study. The only interviewer race effect we found was a main effect for anxiety, but youth with African American interviewers reported less anxiety than did those with White interviewers. This finding is counter to what would be expected from a social-desirability perspective in relation to racial dynamics. The overall mean differences between youth interviewed by White versus African American interviewers, however, were quite small. It is possible that not much should be made of these relatively small effects in only one domain for only one 
variable. Another explanation might suggest that White interviewers may have increased African American students' anxiety in the interview context. It is notable, however, that the interviewers for this study were indigenous to the community in which the students lived. This may have reduced the social distance between them and helped create a less threatening interview situation with White interviewers.

We did find some interviewer gender effects. These analyses indicate that males reported less anxiety and depression when females were interviewing them. This pattern of results suggests that males may be responding to look good to their female interviewers. This may be related to males trying to project a macho image by not looking psychologically troubled. Alternatively, female respondents may be more comfortable disclosing how they feel to a female interviewer. The former explanation supports a social-desirability interpretation, while the latter supports the notion that gender dynamics may influence adolescents' responses in an interview study. Although interviewer and respondent gender interaction was found for academic beliefs in a multivariate analysis, univariate tests did not reveal any group differences. It is also notable that we found no interviewer race or gender main effects for the GPA measures. This suggests further that GPA may not be sensitive information for African American students influenced by interviewer characteristics (Caldwell et al., 1999). Nevertheless, the interviewer gender interaction effects suggest that matching on gender may be worthwhile to avoid potential spurious relationships in our research.

Self-enhancement theories offer another plausible explanation of the high levels of GPA overreporting for this sample (Greenwald, 1980). These theories suggest that low achievers may find questions about their past academic achievement threatening, and overestimate their GPAs to protect their self-esteem (Dobbins et al., 1993; Greenwald, 1980). This may be a viable explanation because only youth who had a GPA of 3.00 or below in eighth grade were included in the study. Although the overall grades for many of these youth improved by the time of the interview, the initial exclusion of the highest academic-achieving students probably resulted in an overrepresentation of lower achieving students in our sample, as compared to the general population. Thus, the fact that the proportion of students who overreported their GPAs is larger than the proportion of overreporters found in other studies is consistent with a selfenhancement explanation. The pattern of relationships between self-reported GPA and all three sets of outcomes in the SEM analyses (i.e., less problem behavior and psychological distress, more academic beliefs) also supports a selfenhancement explanation of the data.

A third explanation may be that our results simply indicate method bias. Selfreported GPA may be related to all the outcomes in the SEM analyses because they all share the same common method variance. Interestingly, the only measure 
collected using a different self-reporting method (i.e., self-administered questionnaire) was associated with both measures of GPA. The alcohol- and marijuanause measures were collected in a paper-and-pencil questionnaire given to respondents when the face-to-face interview portion of the study was completed. All other self-reported data were collected during the face-to-face interviews. These problem behaviors (i.e., alcohol and marijuana use) were collected in a questionnaire format so that youth would feel more comfortable disclosing this sensitive (and in some cases unlawful) information. A questionnaire approach may be most appropriate for collecting sensitive information and when matching interviewer and respondent race and gender may not always be feasible (Caldwell et al., 1999). A method bias interpretation, however, is somewhat mitigated by the fact that we found school-record GPA to be associated with outcomes of sensitive information collected by self-administered questionnaire rather than faceto-face interview. Martin and Nagao (1989) suggest that respondents may be more inclined to provide socially desirable responses during a face-to-face interview than on a self-administered questionnaire. Future research that includes parents and teacher reports, other archival data, or even observational data would provide an opportunity to tease apart the extent to which self-enhancement or method variance may explain the results.

One limitation of this study is that our sample included only youth with eighth-grade GPAs below 3.00. Consequently, our results may not replicate with consistently higher achieving youth. One possible implication of only including youth with GPAs below 3.00 is that we would have limited variance in our data. Yet, the dependent variables in this study have ample variance, and only 3 of 15 study variables have skewness over 1.50 (the largest skew is only 2.53 ). Thus, the distributions of key study variables were not truncated. Our sample is large enough for adequate statistical power to detect small effects. It is noteworthy that other analyses using this sample also produced results that were consistent with the a priori theory being tested (e.g., Doljanac \& Zimmerman, 1998; RamirezValles, Zimmerman, \& Newcomb, 1998; Salem, Zimmerman, \& Notaro, 1998; Zimmerman, Steinman, \& Rowe, 1998). The academic characteristic of our sample may be a strength of the research because it provides an opportunity to test hypotheses among youth not typically studied in isolation. Although eliminating the highest academic-achieving group of students from our sample may not allow for generalizability to broader groups of African American students, it may allow for a better assessment of variations in the reporting behaviors and psychosocial characteristics of African American students with lower GPAs. What is clear from this research is that most African American students with lower GPAs do not engage in problem behaviors or feel bad about themselves (Fine, 1983; Maton \& Zimmerman, 1992; Zimmerman \& Arunkumar, 1994).

Another limitation is that we had to eliminate some youth who did not have school-record GPA data. While this may have influenced some of our results, our 
attrition analyses indicate that youth not included in the study differed on only one study variable. This suggests that the results cannot be explained simply by the fact that the most distressed youth were eliminated. These limitations notwithstanding, we have confidence in the results because they are compatible with past research and were replicated using different analytic approaches.

This study provides a useful examination of the implications of using different methods for measuring GPA among African American students. The SEM and MANOVA results taken together send a cautionary note to researchers who use self-report GPA information in their studies. Whether self-enhancement, social desirability, or method bias account for the results, measures of GPA collected by self-report may provide spurious results, especially if the outcomes studied include school-related variables or psychological well-being. Trice (1990) points out that research relying on self-report of academic achievement may be biased by a large number of overestimates. It is vital to point out, however, that our conclusions are limited to GPA. Researchers who conduct studies that collect only self-reported GPA might be cautioned to limit their analyses with this variable to those that examine problem behavior (e.g., alcohol and drug use). It is likely - especially if the study includes significant numbers of African American youth - that analyses using GPA data as predictors or consequences of psychological distress or school beliefs may be somewhat inaccurate. It may be vital to develop strategies to ensure accurate self-report GPA data if school records are unobtainable. The use of a bogus-pipeline procedure (Jones \& Sigall, 1971) may be one way to ensure a focus on academic performance by the respondent. That is, respondents should be informed that when GPA self-report data are collected, information might also be collected from school-district records. It may also be useful to inform students that teacher ratings of their GPAs will be obtained, to help provide more accurate self-reported GPA information.

Although social scientists are often limited in the type of data that can be collected or that are available, it is necessary to ensure that our data are not biased inordinately by the method of collection. The present study provides additional evidence that it may be especially prudent to be cautious when analyzing selfreported GPA data. Additional studies providing insight into the limitations of different self-reported variables and the influence of the interview situation itself based on race and gender matching of respondents and interviewers would be useful to interpret GPA research findings more precisely, especially among African American youth.

\section{References}

Alexander, K. L., Entwisle, D. R., \& Bedinger, S. D. (1994). When expectations work: Race and socioeconomic differences in school performance. Social Psychology Quarterly, 57, 283-299. 
Armstrong, T. D., Crum, L. D., Reiger, R. H., Bennett, T. A., \& Edwards, L. J. (1999). Attitudes of African Americans toward participation in medical research. Journal of Applied Social Psychology, 29, 552-574.

Barber, B. K., \& Olsen, J. A. (1997). Socialization in context: Connection, regulation, and autonomy in the family, school, and neighborhood, and with peers. Journal of Adolescent Research, 12, 287-315.

Biafora, F. A., Tyler, D. L., Warheit, G. J., Zimmerman, R. S., \& Vega, W. (1993). Cultural mistrust and racial awareness among ethnically diverse Black adolescent boys. Journal of Black Psychology, 19, 266-281.

Brook, J. S., \& Newcomb, M. D. (1995). Childhood aggression and unconventionality: Impact on later academic achievement, drug use, and workforce involvement. Journal of Genetic Psychology, 156, 393-410.

Caldwell, C. H., Jackson, J. S., Tucker, M. B., \& Bowman, P. J. (1999). Culturally competent research methods. In R. L. Jones (Ed.), Advances in African American psychology (pp. 101-127). Hampton, VA: Cobb \& Henry.

Connell, J. P., \& Ilardi, B. C. (1987). Self-system concomitants of discrepancies between children's and teachers' evaluation of academic competence. Child Development, 58, 1297-1307.

Crowne, D. P., \& Marlowe, D. (1964). The approval motive: Studies in evaluative dependence. New York, NY: John Wiley \& Sons.

Derogatis, L. R., \& Spencer, P. M. (1982). The Brief Symptom Inventory (BSI): Administration, scoring, and procedures manual I. Baltimore, MD: Johns Hopkins University School of Medicine, Division of Medical Psychology.

Dobbins, G. H., Farh, J., \& Werbel, J. D. (1993). The influence of self-monitoring and inflation of grade-point averages for research and selection purposes. Journal of Applied Social Psychology, 23, 321-334.

Doljanac, R. F., \& Zimmerman, M. A. (1998). Psychosocial factors and high-risk sexual behavior: Race differences among urban adolescents. Journal of Behavioral Medicine, 21, 451-467.

Dornbusch, S. M., Ritter, P. L., Leiderman, P. H., Roberts, D. F., \& Fraleigh, M. J. (1987). The relation of parenting style to adolescent school performance. Child Development, 58, 1244-1257.

Ellickson, P., Saner, H., \& McGuigan, K. A. (1997). Profiles of violent youth: Substance use and other concurrent problems. American Journal of Public Health, 87, 985-991.

Fetters, W. B., Stowe, P. S., \& Owings, J. A. (1984). Quality of responses of high school students to questionnaire items. Washington, DC: National Center for Educational Statistics.

Fine, M. (1983). Perspectives on inequity: Voices from urban schools. In L. Bickman (Ed.), Applied psychology annual (Vol. IV, pp. 217-246). Beverly Hills, CA: Sage. 
Frucot, V. G., \& Cook, G. L. (1994). Further research on the accuracy of students' self-reported grade point averages, SAT scores, and course grades. Perceptual and Motor Skills, 79, 743-746.

Gamble, V. N. (1993). A legacy of distrust: African Americans and medical research. American Journal of Preventive Medicine, 9(Suppl. 6), 35-38.

Grant, K., Lyons, A., Landis, D., Cho, M. H., Scudiero, M., Reynolds, L., Murphy, J., \& Bryant, H. (1999). Gender, body image, and depressive symptoms among low-income African American adolescents. Journal of Social Issues, 55, 299-315.

Greenwald, A. G. (1980). The totalitarian ego: Fabrication and revision of personal history. American Psychologist, 35, 603-618.

Guthrie, B. J., Caldwell, C. H., \& Hunter, A. G. (1997). Minority adolescent female health: Strategies for the next millennium. In D. K. Wilson, J. R. Rodrigue, \& W. C. Taylor (Eds.), Health-promoting and health-compromising behaviors among minority adolescents (pp. 153-171). Washington, DC: American Psychological Association.

Hankins, B. L., \& Abramson, L. Y. (1999). Development of gender differences in depression: Description and possible explanations. Annals of Medicine, 31, 372-379.

James, S. A., Strogatz, D. S., Wing, S. B., \& Ramsey, D. L. (1987). Socioeconomic status, John Henryism, and hypertension in Blacks and Whites. American Journal of Epidemiology, 126, 664-673.

Johnson, L. D., Bachman, J. G., \& O'Malley, P. M. (1984). Monitoring the future: Questionnaire responses from the nation's high school seniors, 1983. Ann Arbor, MI: Institute for Social Research.

Jones, E. E., \& Sigall, H. (1971). The bogus pipeline: A new paradigm for measuring affect and attitude. Psychological Bulletin, 76, 349-364.

Joseph, J. (1996). School factors and delinquency: A study of African American youths. Journal of Black Studies, 26, 340-355.

Lent, R. W., Brown, S. D., \& Larkin, K. C. (1984). Relation of self-efficacy expectations to academic achievement and persistence. Journal of Counseling Psychology, 31, 356-362.

Lewinsohn, P. M., Gotlib, I. H., Lewinsohn, M., Seeley, J. R., \& Allen, N. B. (1998). Gender differences in anxiety disorders and anxiety symptoms in adolescents. Journal of Abnormal Psychology, 107, 109-117.

Martin, C. L., \& Nagao, D. H. (1989). Some effects of computerized interviewing on job applicant responses. Journal of Applied Psychology, 74, 7280.

Maton, K. I., \& Zimmerman, M. A. (1992). Psychosocial predictors of substance use among urban Black male adolescents. Drugs and Society, 6, 79-113.

Mensch, B. S., \& Kandel, D. B. (1988). Underreporting of substance use in a national longitudinal youth cohort. Public Opinion Quarterly, 52, 100-124. 
Mounts, N. S., \& Steinberg, L. (1995). An ecological analysis of peer influence on adolescent grade point average and drug use. Developmental Psychology, 31, 915-922.

Musgrave-Marquart, D., Bromley, S. P., \& Dalley, M. B. (1997). Personality, academic attribution, and substance use as predictors of academic achievement in college students. Journal of Social Behavior and Personality, 12, 501-511.

Owens, T. J. (1994). Two dimensions of self-esteem: Reciprocal effects of positive self-worth and self-deprecation on adolescent problems. American Sociological Review, 59, 391-407.

Phinney, J. S., Cantu, C. L., \& Kurtz, D. A. (1997). Ethnic and American identity as predictors of self-esteem among African American, Latino, and White adolescents. Journal of Youth and Adolescence, 26, 165-185.

Ramirez-Valles, J., Zimmerman, M. A., \& Newcomb, M. D. (1998). Sexual risk behavior among youth: Modeling the influence of prosocial activities and socioeconomic factors. Journal of Health and Social Behavior, 39, 237253.

Roeser, R. W., Midgley, C., \& Urdan, T. C. (1996). Perceptions of the school psychological environment and early adolescents' psychological and behavioral functioning in school: The mediating role of goals and belonging. Journal of Educational Psychology, 88, 408-422.

Rosenberg, M., Schooler, C., \& Schoenbach, C. (1989). Self-esteem and adolescent problems: Modeling reciprocal effects. American Sociological Review, 54, 1004-1018.

Salem, D. A., Zimmerman, M. A., \& Notaro, P. C. (1998). Effects of family structure, family process, and father involvement on psychosocial outcomes among African American adolescents. Family Relations, 47, 331-341.

Schulenberg, J., Bachman, J. G., O'Malley, P. M., \& Johnston, L. D. (1994). High school educational success and subsequent substance use: A panel analysis following adolescents into young adulthood. Journal of Health and Social Behovior, 35, 45-62.

Schuman, H., \& Converse, J. M. (1971). The effects of Black and White interviewers on Black responses in 1968. Public Opinion Quarterly, 34, 44-68.

Schuman, H., \& Hatchett, S. J. (1974). Black racial attitudes: Trends and complexities. Ann Arbor, MI: Survey Research Center, Institute for Social Research, University of Michigan.

Stein, J. A., Newcomb, M. D., \& Bentler, P. M. (1986). Stability and change in personality: A longitudinal study from early adolescence to young adulthood. Journal of Research in Personality, 20, 276-291.

Thomas, S. B., \& Quinn, S. C. (1991). The Tuskegee syphilis study, 1932: Implications for HIV education and AIDS risk education programs in the Black community. American Journal of Public Health, 81, 1499. 
Trice, A. D. (1990). Reliability of students' self-reports of scholastic aptitude scores: Data from juniors and seniors. Perceptual and Motor Skills, 71, 290.

Wichstrom, L. (1999). The emergence of gender difference in depressed mood during adolescence: The role of intensified gender socialization. Developmental Psychology, 35, 232-245.

Windle, M., \& Windle, R. C. (1996). Coping strategies, drinking motives, and stressful life events among middle adolescents: Associations with emotional and behavioral problems with academic functioning. Journal of Abnormal Psychology, 105, 551-560.

Zimmerman, M. A., \& Arunkumar, R. (1994). Resiliency research: Implications for schools and policy. Social Policy Report, 8, 1-18.

Zimmerman, M. A., Steinman, K. J., \& Rowe, K. J. (1998). Violence among urban African American adolescents: The protective effects of parental support. In X. B. Arriaga \& S. Oskamp (Eds.), Addressing community problems: Psychological research and intervention (pp. 78-103). Thousand Oaks, CA: Sage. 